\title{
ON OUR SCIENCE AND SCIENTIFIC WORKERS
}

\author{
Gjorgji Filipovski ${ }^{1}$ \\ Macedonian Academy of Sciences and Arts
}

Corresponding author: Gjorgji Filipovski, Macedonian Academy of Sciences and Arts, Bul. Krste Misirkov, No. 2, Skopje, Republic of Macedonia

The idea to write this text comes from the scientific conference held in the Macedonian Academy of Sciences and Arts (MASA), held on October 10, 2016 devoted to the situation and perspectives of the higher education (HE) and the scientific and research activities (SRA). During the preparations for the conference, a study by Acad. Vlado Kambovski Dispute on science and the higher education in the Republic Macedonia in the 21st century was published in MASA. Many statistics and official reports on the situation were presented therein.

I would like to give an overview of the development of science over the seven decades since the liberation to present days. I would like to discuss the pressing problems of our science that are awaiting a solution, in addition about the concern of the state for the development of science, the ups and downs of this development, the status of the researchers in the various stages of that development. Undisputed is the fact that a tremendous progress has been done to reach the present state with large capacities in buildings, equipment, personnel, etc. planned for science and higher education.

On these issues I will talk less using statistical figures, and I will talk more from the standpoint of a scientist, the way he has experienced it, as a living witness and a direct participant in the SRA and the HE for 70 years. It seems I am the only living witness.

I was fortunate and privileged to follow that developments from the first day after the liberation. In December 1944 I started my scientific career at the
Institute of Agriculture. In the autumn of 1947 I was selected in the first Teaching Council of the Faculty of Agriculture and Forestry as the youngest lecturer. I was also a member of the first academic community when the University was established in 1949. I continued the SRA and the HE activities at the Faculty of Agriculture until 1983, i.e. until the retirement (three years of activity at the Institute and 36 years of higher education activity). Even after the retirement to present days I have continued that activity at the Faculty of Agriculture and at the MASA. In that long period science passed through many stages, and also changed the state's concern for science. The status of the scientific workers changed as well.

Memorable are the first 10-15 years after the liberation with a maximal concern of the state for the development of science, higher education and culture, a concern that even until today has not been repeated. This concern pulled the country out of a terrible backwardness.

In those days, for a short period of time things have happened, for which in other Balkan countries it took decades, and in the old and developed countries it took even centuries. For e.g., at the beginning of 1945 the alphabet was adopted and the literary language was codified. In 1946 the Faculty of Philosophy was established, where for the first time a word in the Macedonian language was heard at a higher education institution. In 1949 the Skopje University was established. Only 4 years passed from alphabet to university. It is unknown in the history of the European nations. 
After the liberation we were a total of slightly more than ten scientific workers, of whom only a few were doctors of science, and only three were former lecturers at the Belgrade University. I was only 25 years old and I had an experience of three years as an assistant at the Sofia University. We all became teachers - members of the first academic community at the first university in 1949. At that time the University had less than 100 professors. That was the nucleus from which developed all that we have today in science and higher education. We, the professors, had a privileged profession in the society in those days. We had a higher salary than the others, and we had especially good supply when others barely survived with coupons. Also, with the election for teachers we received approvals for individual apartments, i.e. a big premium for that time when the majority of the citizens lived in shared apartments. I am not mentioning the privileges because I wanted them, but only as an illustration of the great concern of the state for the science and the scientists. Many universities and scientific institutes were established and built in that period.

Of course it could not have lasted forever. A period of stable development of the science from budget funding came, and I would say satisfactory for the possibilities of that period. Later the Council for Scientific Work and the Fund for Funding of Scientific Work were established. For some time I was the head of those bodies, so I know how big was the role of the scientific workers in the creation of science policy and funding of the scientific activities. The budgetary funding was replaced with a fund one, which was more successful. Unfortunately, then came the period when the self-management was introduced, i.e. the establishment of basic organizations of associated labor. This concept was taken from the economy, but applied in the higher education and in science it proved unsuccessful and caused regress in these activities. The scientific workers in their faculties and institutes lost much of their meaning and influence.

A few years before the independence the troubles began. With the independence they intensified. The Council and the Fund were abolished. The scientific workers lost their influence. The funding deteriorated and a period of stagnation and even regression in the SRA has come. The situation worsened further in the last decade when the problems have intensified, which will be discussed later. Science and scientific workers were on the margins of society, sometimes even ignored and discredited. This will also be discussed. Some things that have improved science will not be forgotten.

This article reflects my personal opinion and the responsibility is mine.
Let's start with the problems in our science.

On some pressing problems of our science.

During the 7 decades of free life in the development of science in our country many problems occurred. I chose to write about 5 of the most important, which in the last decade have arisen in particularly enhanced form. Those are:

1. Low percentage of gross domestic product (GDP) allocated for science.

2. Lack of assets for funding scientific and research projects.

3. Blocked election of young scientific workers.

4. Small number of researchers in comparison with the European standards.

5. Non-participation of scientific workers in the creation of the science policy.

According to the World Bank report, the percentage of the GDP in the Republic Macedonia allocated for science is the lowest in the region and in Europe. Usually this percentage shows the concern for science in individual countries. For the whole period since the independence to present days this percentage has ranged from $0.17 \%$ to $0.24 \%$ with a mean value of around $0.22 \%$. In some other countries in the region this is significantly more (Serbia $-0.8 \%$, Croatia - 1.1\%). The European countries on average allocate about 3\%, and some European countries even more. Some Asian countries with a rapid development allocate even twice as much as Europe. The EU recommendation for the European countries is $3 \%$, i.e. more than 10 times than us. According to the program of the Ministry of Education and Science (MES) it is planned this percentage in the Republic of Macedonia in 2016 to be $1 \%$, and $1.8 \%$ by 2020 , but it has not been realized. 6.5 euros are allocated per capita in the Republic of Macedonia and nearly 500 euros in Europe. This percentage was increased in the Republic of Macedonia in $2012(0.33 \%)$ and in $2013(0.44 \%)$. However, it has not improved the projects financing, because this increase was due to the procurement of laboratories and translation of literature. The newly procured equipment will improve the working conditions in the scientific institutions, but without the funds for projects the new equipment will remain underused. Concerning the funds for translation, many feel that they would be more usefully and more effectively used if they were given to the libraries of the scientific institutions for the procurement of foreign literature and journals. Many of the translated books have been earlier used in the original by the researchers.

Nowadays, in the information society, which is based on knowledge and scientific achievements, 
the investments in science accelerate the overall development of a country. It is proven by the most developed countries and by the developing countries with very rapid development.

The insufficient projects funds is the constant problem of our science. The funds allocated for science are used for salaries, material costs and projects. The Projects funds are constantly reduced and we have reached the present situation when these funds are rarely granted, and possibly for bilateral projects, i.e. for joint projects with other countries, in a modest amount.

The Vice Rector for science of the University of Ss. Cyril and Methodius (UKIM) recently said that in the last 10 years UKIM has not received funds for scientific and research projects. This fact has several negative consequences: the enormous resources invested in science in these seven decades of free life (for buildings, equipment, personnel, etc.), remain unused or underused. In order to make these investments "operable" only a small percentage of those assets is required. Moreover, the lack of funds for projects reduces the scientific production and represents a major problem for the advancement of the scientific workers. Papers are arguably required from them, but no funds have been provided for the papers. In addition, the lack of these funds makes it difficult to prepare the young generation for science because it requires participation in the projects implementation. The lack of funds for science is one of the reasons why UKIM is not among the top 500 universities in the world, unlike, for example, Belgrade and Zagreb University.

This lack of funds for scientific and research projects was experienced by me and my associates. For more than 8 years we have been searching, in vain, means to complete the project for preparation of 63 soil maps and 11 studies on our soils. All the necessary scientific materials have been collected over many decades. The project was successfully completed thanks to the understanding of FAO (UN agency), which has granted us 340,000 dollars from its fund for science. We were embarrassed in front of their experts who helped us because they have shown greater interest in our soils than our country.

The funds for projects and for election of young scientific personnel have been reduced or cancelled in addition to the realization of the concept of combining the lowest GDP per capita with the highest number of universities per million inhabitants in Europe. This concept has been applied only in the Republic of Macedonia. New universities are also established. The concept does not meet our financial and personnel capabilities and needs. It is based on the illusion that quantity replaces quality. A good expert cannot be replaced with 5 trained persons with insufficient knowledge. Practice has shown that this concept has not reflected positively on the level of the higher education and science. I would like to note that in this region there are usually about 3 to 4 universities per million inhabitants, and in some rich countries (California, France) below 2. In the Republic of Macedonia there are 12. Maybe it should be considered to review this concept.

The third and perhaps most painful problem is blocking the election of a scientific offspring. Full professors retire each year, and there is no mechanism to train young and proficient scientists. For this purpose there used to exist funds for assistants that, by engaging in teaching, through completing masters and doctoral studies, which lasted about 8 years in total, were well trained for election into Docent title. By abolishing the assistantship positions the funds for scientific offspring were abolished. I know that there are other ways of training. But they cannot be based on a voluntary basis. The Faculty of Agriculture Sciences and Food, where I was a Professor for 36 years now has only one assistant. In my time, only for my subject there were 2 assistants, i.e. more than at the entire Faculty today. The state of the scientific offspring, unfortunately is similar at the other faculties, too. Without young scientific personnel science has no future. In our country, fortunately, there is plenty of capable personnel who has graduated with high marks and to whom the doors of the universities are closed. They are knocking on other doors abroad.

In the last decade on budget funds tens of thousands of young people with completed studies have been employed. The media reported that some of them stayed at home and received salaries, including those at the Ministry of Education and Science. Only a small percentage of that large number (1-2\%) would be sufficient for UKIM to obtain, for example, a thousand young talented and promising people, for each faculty of about 50 that will secure its own future. There are no justified reasons why this has not been done or why it is not being done.

The consequence of the small funds given to science in our country is the small percentage of researchers, especially young people, on 1,000 employees compared with the European countries, where we are striving. According to the World Bank data, in 2007 in our country there were 1.6 researchers per 1,000 employees, 3.4 in Bulgaria, 3.6 in Croatia, and 6.6 in the EU. Numbers speak for themselves.

Finally something about the participation of researchers in the creation of science policy. Today 
there are, at national level, bodies in which participate scientific workers, too, within which are proposed strategy, program and funding of the SRA aligned with the overall development of the country. The opinion of the researchers is less important than the opinion of some employees of the MES, which have never dealt with science. It was not always like that. After the independence the Council for scientific work and the Fund for SRA were abolished. With the abolition of the Fund, the fund financing was replaced with a budget financing where scientific workers do not participate and which has far fewer resources. This situation has continued until present days. With the Law on SRA an attempt has been made after two decades to renew the work of these bodies. Relevant legal provisions have been adopted, but concerning the participation of the scientific workers, those legal provision for several years have not been implemented in practice. I do not think that anyone can benefit from it.

I can remember the following matters that have improved science over the past seven decades:

1. The period of the first 10 to 15 years after the liberation when science had a high priority, and in addition, the researchers had a privileged status.

2. I remember in that period the quite unexpected decision to vacate the largest newly built building in Skopje, which belonged to the Ministry of Interior in order to accommodate therein several faculties for which new buildings have not been built. It was unexpected to us, because we knew what an important role that Ministry had in the society in those days. Unfortunately, the earthquake destroyed this building. It was opposite to the Holiday Inn hotel, which is now a parking lot.

3. The financially unlimited support of the University for mitigating the damages of the Skopje earthquake. In a short period of time the university buildings, dormitories, professors' apartments were reconstructed and new buildings for several faculties and dormitories were built. I remember that period well because as a Rector I had the major task to restore and build the University.

4. Great incentive for the promotion of science and art was the investment of large funds for the construction of the new building of MASA and later, after the independence, its annex, too.

5. I remember, as a good one, the decision to establish the Council for Scientific Work and the Fund for Funding of Scientific Work because scientific workers have become a factor in the creation of science policy and funding of scientific activities.
6. I also remember, as a good one, the expert Government and the first parliament that were willing to do everything for science in the situation of the weak opportunities in that period.

7. The group of positive decisions includes the Decision from some years ago to invest in the procurement of new laboratories.

Since the independence the development of science has been stagnant or has been going down. The funds for SRA are reduced, there are not new investments in the university buildings, the scientific facilities and equipment. The funds for scientific and research projects and for the selection of young scientific workers have been abolished. This is especially true for the last decade.

Here are some other items that confirm the marginalization of science and scientific workers, and in some cases their ignoring and discrediting:

Several years ago the Ministry of Science was abolished and was merged with the Ministry of Education. In the joint Ministry the funds for science are reduced and flow into education.

In the joint Ministry of Education and Science, science has a subordinate role not only with the loss of the funds allocated for it. We do not know whether this Ministry has an assistant minister for science because we have not heard from him nor we have seen him. The Ministry's main concern is the education, of which they constantly talk about. We have not heard a word about science. We do not have information about the activities of that Ministry in proposing measures for promoting science. We have not heard that analyses of the situation in science are performed. There is not much desire to hear the opinion of the scientific institutions and scientific workers.

The scientific community has not been informed whether the Government and Parliament periodically consider the state of the SRA and whether they propose measures for its improvement.

The provisions of the Law on SRA relating to the participation of scientific workers in the creation of science policy are not implemented. For example, the National Council for Higher Education and SRA and Technical Development has not been constituted. According to the Law it should be composed of representatives of the Government, the academic community and the business community. The Council for SRA has not been constituted, which is imagined as an expert advisory body to the Minister of Education and Science. The Board of Ethics has not been constituted. All this says that there is no desire to hear the opinion of the scientific workers. One gets the impression that the opinion of 
some Ministry employees, who have not worked in science, is more important than the opinion of those who know better what science is.

Since the independence the Parliament has not reached a Long-term strategy for development of HE and the SRA, although laws have provided for that.

In the last several years the Parliament has not adopted a program for the development of the SRA.

Not even the fund on financing the SRA has been constituted, although such funds exist in all countries. The Council for Scientific Work and the Fund for Funding the SRA have been canceled with the independence.

SRA is still treated as an expense rather than as one of the most important pillars on which rests the rapid, stable and sustainable social development.

Lately, some things occurred that clearly illustrate the marginalization and ignorance of science and scientists:

I will begin with the "11 October" award of some time ago. The law provides these prizes for lifetime achievement to be awarded for achievements in science, culture, economy and other social activities. This year, four prizes were awarded and all just in the cultural area. As far as I know, this is the first time that a prize in the field of science has not been awarded. Isn't there anybody who has deserved it? Do they who award prizes know that among scientists there are acknowledged one, not only in the country, that there are those who have also received international acclaims and those who have been visiting professors at prominent universities? Is this the way to treat science and scientific workers?

I will continue with other examples.

This spring, the highest prize "Goce Delchev" was awarded for achievements in the field science in the previous year. I was one of the winners and I was asked to express appreciation on their behalf. When I looked in the audience with the intention to greet the officials, I realized that there wasn't anyone of the top figures of the country. There wasn't any minister. Not even the Minister of Science was present. There wasn't a single representative of the Assembly. Only the deputy minister of science and education was present. There were no television cameras. Among the papers only "Vest" announced the awards and the names of the winners. Only silence from the other newspapers. It is good that is not the case when awarding prizes in other areas. We, the awardees, asked ourselves - why have we deserved this treatment of ignoring the scientific workers. It was not always like that. When I was awarded the "11 October" award twice (before and after the independence) fortunately it was not like that.
However, it is not only this. The winners of the highest state awards and only in the field of culture are awarded pension supplement to a certain amount. It is also received by singers - performers of folk songs. It is a welcomed gesture. Many scientific workers have expressed me dissatisfaction why it does not apply to them. Is it a coincidence or they are forgotten or something third? That third is called discrimination.

I will describe another case of ignoring the science and the scientists. On October 10, on a Solemn meeting MASA marked the 49th anniversary of its foundation. At the same time, MASA declared two prominent foreign scientists for holders of the international recognition "Blaze Koneski" for the study and promotion of our science and culture. Then, a scientific conference was held with 13 papers focusing on the state and prospects of higher education and the scientific and research activities. Again, there wasn't any official, not even one person from the Ministry of Education and Sciences to hear the real situation in those areas and the proposals for its improvement. Maybe that's why they did not come, so as not to spoil their idealized image for those areas, far from the true one. If they were not willing to hear, at least they could have listened.

Now, a few words about the attitude of the media towards science and scientists. In several newspapers every day, one to two pages are devoted to culture, which is to be welcomed. However, about our science, the various scientific events, the achievements of scientific institutions and the scientific workers, about the received awards you will find in the newspapers from time to time only short articles. Again ignoring. Unfortunately, this situation is not without the fault of the researchers themselves.

I was thinking how to finish this article about the unsatisfactory situation in the area of our science. Reading for the second time the book "On Macedonian Matters" by our great personality Misirkov, I noticed a passage about the importance of science and culture. That paragraph in the original is the following: Science and literature are the most important factor in the development of a nation to become a nation. The degree of development of science and literature in a nation is measured with its culture and that is how nations are divided: those with cultural and those without culture; those with culture rule, and those without culture are slaves. It was written 100 years ago by a man with a true vision for comprehensive development of his people when it will be liberated. Do those that today reach decisions about science have the vision of Misirkov from 100 years ago?

Can the current situation in science be improved? Of course it can. It requires a turnabout. 
First, in the understanding, as a prerequisite for all other changes. This means that science cannot be treated as an expenditure, but as a very important factor without which there cannot be a quick, overall social progress in the country. Science is treated like that in all developed countries and in the countries with rapid development. All minds that know and can suggest a good strategy for a long-term development of the SRA need to be mobilized, and, also to suggest a program for the implementation of the strategy on shorter timelines. That proposal should be considered by the authorities (Government and
Parliament) and a strategy and program to be adopted. It will be the easy part of the job. The implementation is more difficult. This requires a lot of political will, a lot of energy, a lot of money $\backslash$ deep reforms, consistent with the country's needs and the recommendations of the EU, towards which we strive. Scientific workers are not hopeless. They expect the turnabout to begin next year with the formation of a stable government, regardless of who will form it. They are deeply convinced that countries with such situation in science, such as ours, cannot have a bright future. 